\title{
Aspectos envolvidos na contratação e manutenção do personal trainer: capitais em jogo
}

\author{
Aspects involved in hiring and maintaining a personal trainer: capitals at stake \\ Aspectos involucrados en la contratación y mantenimiento de un entrenador personal: \\ capitales en juego
}

Jhonatan Henrique Dias da Silva ${ }^{a}$ (D) , Alan Camargo Silva** (D), Felipe da Silva Triani ${ }^{\mathrm{b}}$ (D), Silvio de Cassio Costa Telles $^{c}$ (D) , Sílvia Maria Agatti Lüdorfa (D)

Palavras-chave: Educação física e treinamento; Sociologia; Academias de ginástica; Mercado de serviços de saúde.

\section{Keywords:}

Physical education and training; Sociology; Fitness centers; Marketing of health services.

\section{Palabra clave:}

Educación y entrenamiento físico; Sociología; Centros de acondicionamiento; Comercialización de los servicios de salud.

\begin{abstract}
RESUMO
Objetivou-se analisar os aspectos que influenciam na contratação e na manutenção do personal trainer, no ponto de vista dos clientes. Para a composição da pesquisa, usuários do serviço responderam questionários e entrevistas. Detectou-se que vários capitais estão em jogo, mas os clientes enfatizaram aspectos simbólicos relativos ao conhecimento, segurança e confiança no seu trabalho como diferenciais. Ao invés de valorizar o capital corporal, como apontado em outros estudos, a investigação observou a emergência do capital perfil como elemento de distinção.
\end{abstract}

\begin{abstract}
RESUMEN
El objetivo fue analizar los aspectos que influyen en la contratación y mantenimiento del entrenador personal, desde el punto de vista de los clientes. Para la composición de la encuesta, los usuarios del servicio respondieron cuestionarios y entrevistas. Se detectó que varios capitales están en juego, pero los clientes enfatizaron aspectos simbólicos relacionados con el conocimiento, la seguridad y la confianza en su trabajo como diferenciales. En lugar de valorar el capital corporal, como se señaló en otros estudios, la investigación observó el surgimiento del capital de perfil como elemento de distinción.
\end{abstract}

a Universidade Federal do Rio de Janeiro, Escola de Educação Física e Desportos, Núcleo de Estudos Sociocorporais e Pedagógicos em Educação Física e Esportes, Rio de Janeiro, RJ, Brasil

b Universidade Estácio de Sá, Rio de Janeiro, RJ, Brasil

c Universidade Federal do Rio de Janeiro, Escola de Educação Física e Desportos, Programa de Pós-graduação em Educação Física, Rio de Janeiro, RJ, Brasil

\footnotetext{
*Autor correspondente:

Alan Camargo Silva

E-mail:alan10@zipmail.com.br
} 


\section{INTRODUÇÃO}

Pode-se considerar que o personal trainer se tornou um dos profissionais mais requisitados na seara da prática orientada de exercícios, não apenas no âmbito de academias de ginástica, mas em espaços públicos ou privados. Cada vez mais, observa-se pessoas realizando práticas corporais sob supervisão deste, reconhecido como "profissional formado/graduado em Educação Física que ministra aulas personalizadas, formulando e executando programas de treinamentos específicos para cada aluno" (Sanches, 2006, p. 51). Harvey et al. (2014) apontam que o personal trainer costuma ser contratado para planejar e acompanhar o treinamento, assim como motivar o cliente, ao assessorá-lo no alcance dos objetivos, por meio de exercícios prescritos de forma individualizada.

Apesar de o treinamento personalizado ter chegado ao Brasil na década de 1980, o aumento na contratação do personal trainer ocorreu principalmente na década de 1990, associado ao avanço técnico-científico sobre os benefícios da atividade física planejada e ao crescente incentivo, ou apelo midiático, às pessoas para que sejam fisicamente ativas (Bossle e Fraga, 2011; Gomes e Caminha, 2014).

Vários são os estudos sobre personal trainer publicados nos últimos anos, tais como relacionados ao marketing (Bossle e Fraga, 2011) ou às características gerais e perfil deste profissional (Mineiro et al., 2013; Silva et al., 2016b). Outras investigações abordam aspectos motivacionais associados à sua atuação (Rodrigues e Brandão, 2017). Entretanto, raras são as pesquisas que se dedicam a compreender o ponto de vista dos clientes sobre os aspectos envolvidos na contratação e manutenção do personal trainer em uma perspectiva sociocultural.

Pretende-se avançar nesta lacuna, com base na argumentação de que a adesão e/ou manutenção do serviço de personal trainer pode ser multifatorial. Um dos possíveis referenciais teórico-metodológicos que podem auxiliar a aprofundar ou desnaturalizar a realidade desse profissional é a perspectiva sociológica proposta por Bourdieu (2004). Nesse estudo, pretende-se operar especificamente com a noção de capital, amplamente discutida por Bourdieu (1983a, b, 1986, 1989, 2014), em suas diferentes formas, tais como: capital econômico, cultural e social ${ }^{1}$.

Importante pontuar que a teoria bourdieusiana se pauta em diversos conceitos interdependentes com o capital como, por exemplo, campo, poder, prática, habitus etc. e que há cada vez mais a necessidade de rigorosos e

1 Para Bourdieu (1986), há três tipos: capital econômico, que são os bens econômicos tradicionais, como dinheiro, casa, carro; capital cultural, relacionado aos códigos culturais, como educação formal, titulação acadêmica (institucionalizado), assistir a peças de teatro, filmes (encarnado), posse de bens culturais como obras de arte (objetivado); e capital social, ligado aos recursos disponíveis pela rede social, ou seja, o ambiente no qual está inserido, conforme classe social e pessoas de convivência. sistemáticos aprofundamentos desse referencial na área de Educação Física (Brasil et al., 2020). Em que pese o legítimo argumento de que a noção de capital não pode ser analisada de forma estática ou isolada, aqui se defende, com base em Catani (2011), o exercício epistêmico-prático de desvendar os mecanismos que tensionam os agentes em dado lócus, no caso, as relações entre clientes e personal trainers.

Como em qualquer interação ou contexto social, os capitais bourdieusianos estão presentes na relação entre personal trainer e cliente no momento da contratação e/ ou manutenção do serviço. Hutson (2013) relata que o capital corporal é visto como elemento essencial para a atuação no âmbito do fitness, pois está associado à certa autoridade moral e de saúde. Christensen e Carpiano (2014) apontam que os capitais privilegiados pelas pessoas que contratam esses profissionais levam o personal trainer a se adaptar à lógica de consumo de cada cliente.

Assim, espera-se ampliar as possibilidades de análise e/ou oferecer uma alternativa de interpretação em relação à atuação do personal trainer, visto que a noção de capital permite repensar a relação laboral e de convívio entre esse profissional e seus clientes. Ademais, pode colaborar para fomentar reflexões e possibilidades interpretativas sobre a atuação dos profissionais que atuam no treinamento personalizado.

O presente empreendimento investigativo não somente pode revelar algumas das demandas de mercado de trabalho para o personal trainer, como também indicar até que ponto certas lógicas socioculturais imperam no consumo de determinados serviços privados de saúde no campo das práticas corporais. Tais aspectos podem auxiliar a ampliar a perspectiva acadêmico-profissional de estudantes e profissionais da área, assim como de outras correlatas, já que faz pensar em quais sentidos o trabalho com as práticas em saúde está alinhavado aos interesses daqueles que conseguem consumir determinados serviços.

Diante do exposto, o objetivo do estudo foi analisar os aspectos que influenciam na contratação e na manutenção do personal trainer, no ponto de vista dos clientes.

\section{PROCEDIMENTOS METODOLÓGICOS}

O presente estudo qualitativo busca compreender o significado dos fenômenos dentro de um contexto social e cultural (Turato, 2011). Para além de quantificar ou mapear os motivos pelos quais os clientes escolhem e continuam com o personal trainer, pretende-se compreender as razões e conhecer os aspectos relacionados à contratação e manutenção do serviço.

A geração do material empírico foi realizada a partir de questionários e entrevistas, o que caracteriza o processo de triangulação de diferentes métodos. Esta combinação fornece mais detalhes sobre a narrativa dos sujeitos, ambiente de trabalho, atitudes, valores, motivações, relações das pessoas e dos grupos sociais em que estão incluídas (Gaskell e Bauer, 2010). Os roteiros do questionário e da entrevista seguiram tópicos-guia semelhantes, que consistiam em: dados de perfil do respondente; informações 
sobre o treinamento com o personal trainer (regularidade, sessões, tipo de treinamento, objetivos, resultados); motivos para a contratação e características desejadas de um personal trainer; comparação da prática de atividade física antes e depois da contratação; motivos para eventual interrupção do serviço de personal trainer.

O questionário possibilita mais tempo e autonomia para exprimir as respostas, na medida em que permite ao ator social se sentir mais livre para expor suas opiniões (Goldenberg, 2004). As entrevistas semiestruturadas, por sua vez, permitem a interação com o entrevistado e a abordagem mais detalhada (Lüdorf, 2017), neste caso, de determinados aspectos, tais como: motivos relacionados à contratação do personal trainer, características do profissional que prevaleciam na escolha e as práticas corporais realizadas durante o treinamento personalizado.

Os mesmos critérios foram adotados para a seleção dos participantes, tanto para os questionários, como para a realização de entrevistas, quais sejam: a) Ter contratado o serviço de um personal trainer, pelo menos uma vez, até 5 anos antes dos questionários ou entrevistas serem aplicados, ou estar treinando com o profissional no momento da pesquisa; b) Possuir idade igual ou superior a 18 anos. Optou-se por pessoas que tem ou já tiveram contato recente anterior com o personal trainer, a fim de que os dados analisados não fossem de décadas ou épocas distintas.

No que se refere à operacionalização da pesquisa, é importante esclarecer que os questionários e as entrevistas não foram aplicados aos mesmos sujeitos. Inicialmente os questionários foram disponibilizados na internet e divulgados através da rede social Facebook, durante os meses de janeiro de 2017 até maio de 2017. Na época do estudo, o Facebook era uma das redes de maior popularidade, com elevado número de usuários, por ser considerada a "rede social da moda" (Ferreira e Arruda, 2015). Assim, o convite para participação foi distribuído em grupos voltados para a área de treinamento, saúde e Educação Física, a fim de atrair um maior número de praticantes. Para Wilkerson et al. (2014), a coleta de dados online se configura por uma forma metodológica legítima e usual na pesquisa qualitativa, pois possibilita compreender o mundo em que vivemos, ou seja, onde a tecnologia é parte integral da vida cotidiana.

Já as entrevistas foram realizadas de modo presencial e individualmente, durante os meses de julho de 2017 a outubro de 2017. Cabe destacar que, se no questionário prevaleceu a impessoalidade, as entrevistas propiciaram interagir com os atores sociais e, por este motivo, optou-se por utilizar a técnica de snowball (Bernard, 2011). Assim, a partir de uma rede inicial de eventuais contatos e da aplicação dos critérios mencionados, obteve-se outras indicações de modo sucessivo. As entrevistas foram realizadas em local escolhido pelo participante, de modo a não prejudicar sua rotina e tiveram duração aproximada de 30 minutos. Mediante consentimento, foram gravadas por meio de aparelho celular e transcritas integralmente.

Dentre os 78 questionários recebidos, cujos participantes preenchiam os critérios de seleção mencionados, 63 foram respondidos por mulheres e 15 por homens, com idade de 18 a 55 anos (maioria entre 24 a 30 anos). Ressalta-se que 49 pesquisados eram residentes na cidade do Rio de Janeiro, sendo 27 da zona norte e 22 da zona sul da cidade. Havia um maior contingente que possuía formação em Ensino Superior, com renda em torno de 4 a 10 salários-mínimos e realizava seus treinos em torno de duas vezes na semana, geralmente em academias de ginástica.

Em relação às entrevistas, foram realizadas 16 , considerando-se o princípio da saturação teórica, ou seja, a suspensão de novos participantes quando os dados passaram a apresentar redundância ou repetição (Turato, 2011). As principais características dos entrevistados são apresentadas a seguir, no Quadro 1.

Quadro 1. Características dos entrevistados.

\begin{tabular}{|c|c|c|c|c|}
\hline Clientes & Idade & Formação acadêmica & $\begin{array}{l}\text { № de vezes por semana de } \\
\text { treinamento personalizado }\end{array}$ & Local de treinamento \\
\hline ME1 & 27 & Ensino superior & 2 a 3 vezes & Academia de ginástica \\
\hline ME2 & 30 & Pós-graduação & 3 vezes & Academia de ginástica \\
\hline ME3 & 51 & Ensino superior & 2 a 3 vezes & Academia de ginástica \\
\hline ME4 & 50 & Ensino superior & 2 vezes & Academia de ginástica \\
\hline ME5 & 42 & Técnico em Enfermagem & 3 a 4 vezes & Academia de ginástica \\
\hline ME6 & 58 & Pós-graduação & 2 vezes & Academia de ginástica \\
\hline ME7 & 24 & Ensino superior & 2 a 3 vezes & Academia de ginástica \\
\hline HE8 & 62 & Ensino superior & 2 vezes & Academia de ginástica \\
\hline ME9 & 58 & Ensino superior & 2 vezes & Em casa \\
\hline ME10 & 42 & Pós-graduação & 2 a 3 vezes & Academia de ginástica e orla da praia \\
\hline ME11 & 52 & Ensino superior & 2 vezes & Academia de ginástica \\
\hline HE12 & 29 & Ensino superior & 2 a 3 vezes & Academia de ginástica e praia \\
\hline ME13 & 61 & Pós-graduação & 3 a 4 vezes & Academia de ginástica, calçadão e praia \\
\hline HE15 & 52 & Ensino superior & 3 a 4 vezes & Academia de ginástica e calçadão \\
\hline ME16 & 50 & Pós-graduação & 2 a 3 vezes & Academia de ginástica \\
\hline
\end{tabular}

As letras $\mathrm{H}$ e $\mathrm{M}$ correspondem ao sexo do(a) entrevistado(a), sendo $\mathrm{H}$ para homens e $\mathrm{M}$ para mulheres. Já a letra $\mathrm{E}$ corresponde ao indivíduo que foi entrevistado. Fonte: elaborado pela autoria. 
Os dados derivados dos questionários e entrevistas foram tratados com base na análise de conteúdo, composta primeiramente por leituras flutuantes e posterior exercício de categorização temática, conforme os princípios de repetição e de relevância, o qual foge à certa "ortodoxia clássica da análise de conteúdo" (Turato, 2011, p. 446).

Este estudo foi aprovado pelo Comitê de Ética em Pesquisa do Hospital Universitário Clementino Fraga Filho vinculado à Universidade Federal do Rio de Janeiro sob número CAAE: 55667616.8.0000.5257. Registra-se que todos os nomes presentes nesse texto são pseudônimos.

\section{APRESENTAÇÃO E DISCUSSÃO DOS RESULTADOS}

Diante do processo de análise mencionado, emergiram as seguintes categorias temáticas: características do personal trainer, motivos para a escolha desse profissional, motivação ao treinamento personalizado, influência do fator econômico e significados de saúde para os clientes.

A lente interpretativa possibilitada pela teoria sociológica de Bourdieu auxiliou, então, a compreender as percepções de agentes do campo quanto ao trabalho do personal trainer, em especial os capitais em jogo na contratação e manutenção deste profissional. Assim, estes aspectos constituíram o foco do presente trabalho, principalmente em torno das quatro primeiras categorias temáticas.

Ao invés de avançar na exploração das categorias separadamente, optou-se por realizar um exercício epistêmico-prático na tentativa de desvendar determinados mecanismos que tensionam os agentes. Trabalhou-se, portanto, na perspectiva analítica de se debruçar sobre o campo de atuação do personal trainer e as disputas de capitais que atravessam a contratação e manutenção do serviço desse profissional. Tal manejo teórico-metodológico permitiu empiricamente trazer à tona o que preconiza Bourdieu (1989): as relações de força atreladas a certos poderes materiais e simbólicos acumulados pelos agentes que indicam relativa legitimação ou reconhecimento no espaço social. Assim, se no gym de boxe de Wacquant (2002, p. 148) privilegiava-se a ideia de administrar ou "preservar e fazer frutificar seu capital-corpo", sugere-se que, nos espaços fitness, o personal trainer precisa angariar outros atributos que não se relacionam diretamente ao físico.

Neste empreendimento analítico, o capital cultural surge como elemento importante para a contratação e manutenção do personal trainer. O conhecimento técnico e a busca constante de qualificação profissional são valorizados pelos clientes e podem ser percebidos como modos de refinar o capital cultural:

É um profissional qualificado, atualizado com estudos, transparente, atencioso, interessado em preparar um treino de acordo com a realidade do cliente. ( $\mathrm{MQ}^{2}, 24$ anos).

Ah, ele é muito competente, ele gosta de estudar, você vê, ele pesquisa tudo. ( $\mathrm{ME}^{3} 13,61$ anos).

Um bom personal precisa primeiro ser credenciado para atividade. Segundo, é fundamental que ele oriente a atividade para o objetivo do aluno. Digo isso, porque alguns personais passam a mesma série para pessoas com biotipos e metas diferentes. (MQ, 26 anos).

De acordo com os pesquisados, os profissionais que possuem conhecimentos técnicos defasados ou que não estão atualizados precisam investir significamente na própria carreira para se manterem no mercado de trabalho. Em outras palavras, há uma demanda dos clientes no sentido de que o personal trainer invista em um capital cultural, o que agregaria no serviço prestado.

Ao caracterizar o capital cultural, Bourdieu (1986) explica que o rendimento escolar da ação educacional depende do investimento cultural proporcionado pela família e do rendimento econômico e social proporcionado pelo ensino. Desse modo, questiona-se em que medida o personal trainer possui condições objetivas e simbólicas de atentar à adesão ou à fidelização de seus clientes a longo prazo no dia a dia de trabalho, por vezes, extenuante, como detectado por Silva e Ferreira (2017).

Assim, argumenta-se que o investimento do capital cultural pode ser descrito como um tipo de autoaperfeiçoamento, que necessita de um esforço pessoal, pois diferente do capital econômico (dinheiro, bens), ou capital social (direitos, títulos de nobreza) nem sempre pode ser transmitido instantaneamente por presente, herança, compra ou troca (Bourdieu, 1986).

De acordo com Teotonio et al. (2014), existem profissionais que não possuem qualificação ou experiência necessária para atuarem como personal trainer. Contudo, aquele que não estiver preparado para atuar neste âmbito pode gerar prejuízos financeiros e complicações à saúde dos seus contratantes. Tal dado pode explicar, em parte, os porquês sobre a importância que os clientes dão ao conhecimento técnico.

Outro aspecto bastante interessante a ser analisado se refere ao capital corporal, visto que foi possível detectar um cuidado dos clientes ao comentarem especificamente sobre a aparência cultuada pelo personal trainer. Por um lado, houve associações de dado modelo de corpo à saúde:

Ele era moreno, estatura mediana, não era fortão, enorme, era mais pra definido e com aspecto saudável

2 A sigla HQ será para homens que responderam aos questionários e a sigla $\mathrm{MQ}$ para mulheres.

3 A sigla ME será para mulheres que responderam às entrevistas e a sigla HE para homens. 
né? Não era nenhum gordinho comendo chocolate no meio da academia, não, era uma pessoa que passava um aspecto, assim, de saúde. (ME2, 30 anos).

Por outro, e de modo mais enfático, os pesquisados evitavam ser mal interpretados quanto à vinculação do personal trainer ao estereótipo de profissional com corpo musculoso. Os clientes deixavam claro que estavam preocupados eminentemente com os resultados, produzidos pelos seus prestadores de serviço, no corpo dos outros:

Olha, eu acho até, assim, não sei se isso tem muito a ver, mas a clientela dele é uma clientela como eu quero ficar, com um corpo bonito, uma galera, assim, bem apresentável, no sentido de eu ver que tem uns musculosinhos. Um corpo legal, a barriga definida, tudo no seu lugar, mas não exagerado. Tudo como quero ficar, definido, mas com um "musculozinho", "fortezinha". E elas têm esse perfil. Já nos outros personais não senti tanta firmeza. (ME4, 50 anos).

Ele era fora do padrão, ele não é sarado, ele é até um pouco gordinho. [...] Eu conhecia algumas alunas dele e achava que o trabalho dele era bom, porque eu gostava do corpo delas. (ME1, 27 anos).

Assim, apreendeu-se que o capital corporal também está em jogo para a escolha do profissional, no entanto o personal trainer não é visto necessariamente como "espelho", uma vez que há uma preocupação maior com as suas habilidades e competências de atingir metas e alcançar resultados para/ com/ no corpo. Geralmente, os trabalhos relacionados às academias de ginástica apontam a imagem do profissional de Educação Física como influenciador na adesão dos clientes ao treinamento personalizado ou à atividade física nas academias de ginástica (Palma, 2014; Silva et al., 2016a; Palazzi e Cardoso, 2017).

Este achado, contudo, contradiz a importância do capital corporal no âmbito do fitness delineada por Hutson (2013), ao detectar que determinada aparência física do personal trainer - em forma, com musculatura delineada - foi considerada elemento de distinção, ao conferir credibilidade, autoridade moral e de saúde ao profissional. Para Boerner et al. (2021), o aspecto físico influencia nas percepções de competência e de nível de conhecimento do personal trainer. Acrescenta-se ainda que esta exigência por determinados padrões corporais pode impactar na saúde mental dos profissionais atuantes no campo do fitness, como detectado em Mathisen et al. (2020).

Dentre as formas de capital que emergem no âmbito da contratação e manutenção do personal trainer, o econômico emerge de diferentes maneiras. Nota-se que os clientes detêm certo capital econômico para a contratação do serviço, visto que dentre os entrevistados, ao menos, todos realizavam a prática de exercícios supervisionada, no mínimo duas vezes por semana, chegando a quatro sessões semanais. Dessa forma, a condição de poder arcar com os custos desses tipos de serviços revela explicitamente o perfil socioeconômico do grupo aqui analisado. À luz de Bourdieu (1983a), tal aspecto sugere teoricamente que determinados estilos de vida e padrões de consumo impactam nos usos do corpo de contratantes do personal trainer.

$\mathrm{Na}$ visão dos clientes, o custo-benefício parece ser avaliado constantemente para a continuidade do serviço do personal trainer, o que revela a centralidade do fator econômico para a manutenção do treinamento personalizado:

A gente faz um sacrificio sabendo que o custo-benefício é bom, mas às vezes você não tem essa disponibilidade. Esse é o principal fator, se todos não têm, não é porque não querem, é por causa do financeiro, pois se estivesse na condição de todos, todos iriam querer ter. (HE8, 62 anos).

Eu já pensei em parar, mas eu continuo achando que isso tá sendo positivo, então, pra mim, o custo-benefício ainda tá valendo. Ele é um profissional, eu acho que é importante que você tenha uma pessoa te orientando. [...]. Prefiro continuar bancando a ter um problema, até porque já to numa certa idade e não posso ficar arriscando. (ME6, 58 anos)

Todo profissional tem seu valor. Entretanto, muitas vezes deixamos de contratar um profissional destes, pois o apelo financeiro fala mais alto. (HQ, 50 anos)

Eu o achei muito bom! Profissional sério. Assim, bastante atencioso, sempre estava com um cronômetro na mão, usava o tablet pra ver a série, sempre tentava mudar os exercícios [...]. (ME2, 30 anos).

Outro aspecto que revela o capital econômico dos clientes pode ser observado no que diz respeito à (não) utilização dos serviços do personal trainer no interior das academias de ginástica:

O primeiro não tinha academia, então tinha que ser na praia mesmo. [...] Esse atual vive me chamando para ir pra praia, mas acabo não indo, porque na academia tem ar condicionado. (ME13, 61 anos).

É, eu tenho um pouco de preguiça, assim, eu gosto até de dar uma caminhada na Lagoa, tento correr as vezes, mas é porque não é perto da minha casa e a insegurança tem a ver com isso. [...] tenho medo de ser assaltada, tenho medo de levarem meu ipod. $\mathrm{Na}$ academia, tô protegida. Então, a segurança pesa muito pra mim nesse sentido. (ME14, 38 anos).

No caso dos dois personal trainers que eu tive, uma atendia na academia $X$ que era perto da minha casa e na praia, [...] o outro atendia na minha própria residência. Se o personal não tiver disponibilidade das academias próximas, ou não tem um local próximo de 
sua escolha, isso pode ser um complicador. (HE12, 29 anos).

O valor da prestação de serviços desse profissional, em academias de ginástica, normalmente é adicionado ao orçamento já comprometido com a mensalidade do estabelecimento. Ainda que os clientes possam ter acesso a ambientes ao ar livre - também revelador de certa posição de distinção em termos econômicos - preferem o conforto das academias de ginástica ou temem por sua segurança. Por outro lado, nota-se que deter certo capital econômico que permita ao profissional possuir equipamentos e transitar de um local a outro foi considerado um diferencial pela clientela.

Logo, os aspectos materiais problematizados por Bourdieu (1983a) podem ser detectados quando os clientes avaliam se o treinamento personalizado seria mais adequado financeiramente com determinado tipo de "equipamento" ou "tecnologia" e, até mesmo, quando calculam as (des)vantagens do espaço outdoor versus indoor. Tal dado dialoga com a ideia de Boltanski (2004) quando aponta que as condições objetivas também determinam dados usos do corpo ou, em outras palavras, a própria forma de se comportar ou existir corporalmente.

Além da presença dos capitais cultural, corporal e econômico, analisados no âmbito da contratação e manutenção do personal trainer nesta oportunidade, argumenta-se sobre a existência de outro capital em jogo. Isto porque um dos aspectos que emergiu significativamente dos relatos foi a influência do perfil do personal trainer na escolha e manutenção do treinamento personalizado. Determinadas características, na visão dos clientes, interferem diretamente no relacionamento com o profissional:

Ele é um cara normal, que tem uma vida mais como a minha e isso é o que pesa no fim das contas. Ele é o cara que entende a minha limitação e não vai ficar me julgando porque eu saí à noite e cheguei estourada pra fazer aula. [...] ele é um cara que gostava de "biritar" $e$ as vezes me contava as histórias e a gente ria das bebedeiras como eu, acho que isso faz diferença. (ME14, 38 anos).

Ah, a paciência, o jeito dele... assim, de ser um cara legal. A gente tinha bom entrosamento, porque ele montava minhas séries [...]. A academia que a gente tava acabou, fechou, e a maioria foi pra outra academia. Mas eu optei ir pra academia que ele foi pra poder continuar com ele. (ME3, 51 anos).

Se o Luisinho me falar "Tô indo trabalhar na Conchichina", eu vou com ele [...]. É um cara que eu tenho o prazer de encontrar para malhar, sem nenhuma obrigação, [...] é prazer. (HE15, 54 anos).

Simpatia, pois é fundamental que você se sinta à vontade [...] tem que ter bom humor e flexibilidade de horário. (MQ, 36 anos).

Possuir hábitos e modos de agir semelhantes aos do cliente, respeitar as diferenças entre ambos e possibilitar uma relação prazerosa, afetuosa ou de acolhimento durante o treinamento personalizado, parecem ser elementos de diferenciação. Silva et al. (2016b) afirmam que a confiança, a segurança e o cuidado foram fatores determinantes para que alguns alunos trocassem de academia de ginástica, a fim de continuar com o seu treinador, apesar da distância entre os estabelecimentos.

Contudo, considerando-se a noção de capital (Bourdieu, 1986), pondera-se que em relação ao trabalho do personal trainer, se estabelece o que aqui foi denominado de capital perfil. Gerado pela combinação de diferentes capitais, como por exemplo, cultural e social, ou ainda, corporal (Shilling, 2005), nota-se o processo de conversão ao capital perfil. Este tipo de capital, valorizado no campo do fitness, está atrelado ao conjunto das características, modos de falar e de agir, que o cliente reconhece no personal trainer e que influenciariam tanto na contratação, quanto na manutenção do profissional.

Alguns indícios podem auxiliar a compreender melhor como o capital perfil assume posição distintiva no campo. Determinados clientes relataram que antes da escolha do personal trainer observavam suas formas de atendimento, modo como se relacionavam com os outros, ou checavam seus currículos em fichas das academias de ginástica.

Ao observarem a atuação do personal trainer, os clientes se identificam com determinado profissional e optam por contratá-lo devido às características e falas semelhantes, as quais possivelmente são oriundas do contexto cultural e social em que estão inseridos:

Eu via o trabalho que ele desenvolvia durante o tempo que ele estava na sala sendo personal de outras pessoas, e mesmo como profissional trabalhando ali, sem ser personal, [...], parava corrigia a postura, então isso me chamou atenção. Não era só pro aluno dele, mas pra todo mundo [...] prestar seu serviço ou dar atenção, então isso me chamou atenção, e minha primeira escolha foi ele. (ME16, 50 anos)

Porque aqui na academia tem uma ficha deles ali em cima e eu fui olhando pelo perfil de cada um e percebi que aquela personal ia me atender no que eu tinha interesse. (HE8, 62 anos)

O trabalho de Silva e Ferreira (2020) argumenta sobre a importância e a influência da simetria entre o profissional de Educação Física e o aluno no que diz respeito à abordagem relativa às orientações da atividade física em academias de ginástica. De certo modo, tal dado dialoga com o trabalho de Bourdieu (2006) sobre hexis na medida em que a forma como o personal trainer se comporta ou se apresenta corporalmente pode fazer com que o cliente se sinta confortável durante a prestação do serviço. 
Além disso, vale destacar as aproximações entre as relações médico-paciente problematizadas por Boltanski (2004) e as possíveis (não) afinidades entre o cliente e o seu personal trainer, detectadas no presente estudo. Por exemplo, enquanto o diagnóstico e o tratamento de dada doença podem ser modulados a depender da distância social entre o médico e o paciente ao longo das consultas (Boltanski, 2004), as referências ou expectativas corporais dos praticantes face ao profissional de Educação Física também podem ser determinantes na contratação e na manutenção do personal trainer. Em outras palavras, as variadas condições objetivas, experiências e atenções ao corpo e às práticas corporais, identificadas nos agentes, indicam que distintos habitus tensionam o campo e reverberam na adesão ou interrupção da prestação de serviço em tela.

Essas características que influenciam na adesão das pessoas a determinados profissionais que atuam como personal trainer ilustra a relevância do perfil do profissional como um capital que prevalece no treinamento personalizado. O capital perfil se articula com o seu papel socialmente construído nesses espaços fitness, bem como com o auxílio aos clientes para que atinjam seus objetivos e continuem ativos fisicamente (Silva et al. 2016a).

Evidencia-se, portanto, que o presente trabalho demonstra algumas formas ou gostos distintivos de viver a partir das microrrealidades do campo fitness em que, emblematicamente, o personal trainer se torna um "bem simbólico" a ser adquirido, preservado ou eliminado a depender das circunstâncias econômicas, ou ainda, em função do que se lucra socialmente com a adesão a esse profissional.

\section{CONCLUSÃO}

Em termos gerais, o que diferenciou esse trabalho dos demais foi a utilização de algumas das noções trabalhadas por Bourdieu (1983a, b, 1986, 1989, 2014), em especial, o capital. Essa noção bourdieusiana auxiliou na análise do contexto de atuação e da dinâmica ou complexa rede de significados em torno do "ser" personal trainer.

Destarte, notou-se que as noções de capitais delineadas por Bourdieu (1986) podem ser articuladas no contexto do mercado de trabalho deste profissional. Diferentes capitais permanecem constantemente "em jogo" no campo do fitness, e se constituem em elementos de distinção, que potencialmente influenciam na contratação, manutenção e atuação do personal trainer, de diversas formas.

Em síntese, foi possível perceber que os capitais corporal, cultural, e econômico estiveram presentes como fatores que influenciam na atuação do personal trainer. Entretanto, emergiu uma capital diferente dos demais, denominado aqui de capital perfil, um diferencial dessa pesquisa. $O$ capital perfil referiu-se ao conjunto das características, modos de falar e agir, que o cliente reconhece no personal trainer e que influencia tanto na contratação, quanto na manutenção do profissional. Ao invés do destaque à aparência do profissional, como outros estudos indicavam, os clientes enfatizaram aspectos simbólicos relativos ao conhecimento, segurança e confiança na execução e resultados do treinamento, assim como as competências técnicas e de relacionamento do personal trainer.

Defende-se, portanto, que empreendimentos investigativos de cunho sociocultural sobre o contexto de atuação do personal trainer, com base na perspectiva dos clientes, podem fomentar reflexões e possibilidades de análise sobre a atuação dos profissionais que atuam no treinamento personalizado, bem como sobre as relações potenciais entre a intervenção do personal trainer e os distintos nichos de mercado de trabalho. Explorar o ponto de vista dos clientes desses tipos de profissionais significa entender ou sugerir também como dado mercado de serviços de saúde pode ser apropriado ou simbolizado por aqueles que consomem determinados atendimentos voltados a outros cuidados de si. Por fim, é válido reconhecer os limites do presente estudo, ao se pautar em um recorte conceitual específico da teoria bourdieusiana ou ainda, relativos às escolhas metodológicas, em que pesem terem sido profícuas neste caso. Sugere-se, para futuras pesquisas, investigações que explorem não somente outras modalidades de práticas corporais, como também procedimentos metodológicos etnográficos e/ou pela via da observação participante.

\section{FINANCIAMENTO}

O presente trabalho é derivado da dissertação de mestrado de Jhonatan Henrique Dias da Silva, intitulada "Personal trainer e o seu contexto de atuação: corpo, saúde e trabalho", defendida no Programa de PósGraduação em Educação Física da Universidade Federal do Rio de Janeiro, com apoio de bolsa de estudo oferecida pela Coordenação de Aperfeiçoamento de Pessoal de Ensino Superior - Brasil (CAPES).

\section{CONFLITOS DE INTERESSE}

Os autores declaram não haver conflitos de interesse.

\section{REFERÊNCIAS}

Bernard HR. Research methods in anthropology: qualitative and quantitative approaches. 5. ed. UK: Altamira Press; 2011.

Boerner PR, Polasek KM, True L, Lind E, Hendrick JL. Is what you see what you get? Perceptions of personal trainers' competence, knowledge, and preferred sex of personal trainer relative to physique. J Strength Cond Res. 2021;35(7):1949-55. http://dx.doi.org/10.1519/ JSC.0000000000003027. PMid:30893281.

Boltanski L. As classes sociais e o corpo. 3. ed. São Paulo: Paz e Terra; 2004. 
Bossle $\mathrm{CB}$, Fraga $\mathrm{ABO}$. personal trainer na perspectiva do marketing. Rev Bras Ciênc Esporte. 2011;33(1):149-62. http://dx.doi.org/10.1590/S0101-32892011000100010.

Bourdieu P. Sociologia. São Paulo: Ática; 1983a.

Bourdieu P. Questões de sociologia. Rio de Janeiro: Marco Zero; 1983b.

Bourdieu P. The forms of capital. In: Richardson J, editor. Handbook of theory and research for the Sociology of Education. Westport: Greenwood; 1986. p. 241-258.

Bourdieu P. O poder simbólico. Lisboa: Difel; 1989.

Bourdieu P. Coisas ditas. São Paulo: Brasiliense; 2004.

Bourdieu P. O camponês e seu corpo. Rev Sociol Polít. (Impr.). 2006;26:83-92.

Bourdieu P. A produção da crença: contribuição para uma economia dos bens simbólicos. 3. ed. Porto Alegre: Zouk; 2014.

Brasil MR, Oliveira VM, Mattes VV, Marchi Júnior W, Souza J. Os usos da teoria sociológica de Pierre Bourdieu em periódicos científicos da área de Educação Física no Brasil. Rev Bras Ciênc Esporte. 2020;42:e2066. http://dx.doi. org/10.1590/rbce.42.2019.123.

Catani AM. As possibilidades analíticas da noção de campo social. Educ Soc. 2011;32(114):189-202. http://dx.doi. org/10.1590/S0101-73302011000100012.

Christensen VT, Carpiano RM. Social class differences in BMI among Danish women: applying cockerham's health lifestyles approach and Bourdieu's theory of lifestyle. Soc Sci Med. 2014;112(2):12-21. http://dx.doi.org/10.1016/j. socscimed.2014.04.017. PMid:24788112.

Ferreira NS, Arruda EJM Fo. Facebook e whatsapp: uma análise das preferências de uso. Reuna. 2015;20(3):47-64.

Gaskell G, Bauer MW. Para uma prestação de contas pública: além da amostra, fidedignidade e da validade. In: Gaskell G, Bauer MW, editors. Pesquisa qualitativa com texto, imagem e som: um manual prático. 8. ed. Petrópolis: Vozes; 2010. p. 470-90.

Goldenberg M. A arte de pesquisar: como fazer pesquisa qualitativa em Ciências Sociais. 8. ed. Rio de Janeiro: Record; 2004.

Gomes IS, Caminha IO. Um olhar sobre a formação e atuação profissional no Brasil: o caso dos personal trainers. Pensar Prát. (Impr.). 2014;17(1):560-77. http://dx.doi. org/10.5216/rpp.v17i2.25681.

Harvey G, Vachhani SJ, Williams K. Working out: aesthetic labour, affect and the fitness industry personal trainer. Leis Stud. 2014;33(5):454-70. http://dx.doi.org/10.1080 /02614367.2013.770548.

Hutson DJ. "Your body is your business card": bodily capital and health authority in the fitness industry. Soc Sci Med. 2013;90:63-71. http://dx.doi.org/10.1016/j. socscimed.2013.05.003. PMid:23746610.

Lüdorf SMA. Metodologia da Pesquisa: do projeto ao trabalho de conclusão de curso. Rio de Janeiro: Appris; 2017.
Mathisen TF, Aamb $\varnothing$ J, Bratland-Sanda S, Sundgot-Borgen C, Svantorp-Tveiten K, Sundgot-Borgen J. Body figure idealization and body appearance pressure in fitness instructors. Front Psychol. 2020;11:585901. http://dx.doi. org/10.3389/fpsyg.2020.585901. PMid:33424701.

Mineiro L, Scolaro AMT, Barby JÁ, Rocha RE. Perfil dos personal trainers atuantes na cidade de Caçador/RC. Rev Bras Prescr Fisiol Exerc. 2013;7(41):477-83.

Palazzi CA Jr, Cardoso MV. Fatores que impactam a intenção de compra do consumidor do serviço de personal trainer. Podium. 2017;6(4):310-30. https://doi.org/10.5585/ podium.v6i4.248.

Palma A. E como segue a saúde dos professores de Educação Física? Corpus et Scientia. 2014;10(2):1-15.

Rodrigues ALP, Brandão DC. Fatores motivacionais que levam mulheres entre 18 e 30 anos à procura e adesão ao treinamento com personal trainer em uma academia na cidade de Fortaleza-CE. Revista Brasileira de Nutrição Esportiva. 2017;11(62):168-75.

Sanches EW. Responsabilidade civil das academias de ginásticas e do personal trainer. São Paulo: Editora Juarez de Oliveira; 2006.

Shilling C. The body and social theory. Londres: Sage Publications; 2005.

Silva AC, Ferreira J. Corpo "educado": atuação pedagógica de professores de Educação Física em academias de ginástica. R Motriviv. 2020;32(63):1-16. http://dx.doi. org/10.5007/2175-8042.2020e76554.

Silva AC, Ferreira J. Physical Education professionals in fitness centers: body pain as work performance. J Phys Educ (Maringá). 2017;28(1):e2845. https://doi.org/10.4025/ jphyseduc.v28i1.2845.

Silva FIC, Santos AM, Araújo DME. Perfil profissional do personal trainer atuante em academias de Teresina-PI. Rev Bras Prescr Fisiol Exerc. 2016a;10(61):634-44.

Silva ML, Bossle CB, Fraga AB. Em companhia do personal trainer: significados atribuídos pelos alunos ao atendimento personalizado. R Motriviv. 2016b;28(49):26-37. http:// dx.doi.org/10.5007/2175-8042.2016v28n49p26.

Teotonio JS, Baia FC, Teixeira CVLS, Romanholo R, Pereira JE. Perfil dos personal trainers atuantes na cidade de Cacoal Rondônia-Brasil. Rev Bras Prescr Fisiol Exerc. 2014;8(50):855-63.

Turato ER. Tratado da metodologia da pesquisa clínicoqualitativa: construção teórico-epistemológica, discussão comparada e aplicação nas áreas da saúde e humanas. 5. ed. Petrópolis: Vozes; 2011.

Wacquant L. Corpo e alma: notas etnográficas de um aprendiz de boxe. Rio de Janeiro: Relume Dumará; 2002.

Wilkerson JM, lantaffi A, Grey JA, Bockting WO, Rosser BRS. Recommendations for internet-based qualitative health research with hard-to-reach populations. Qual Health Res. 2014;24(4):561-74. http://dx.doi. org/10.1177/1049732314524635. PMid:24623662. 